\title{
Metacognitive Experiences: Response to Commentaries
}

\author{
Norbert Schwarz \\ University of Michigan
}

\begin{abstract}
The stimulating commentaries by Huber (2004), Lee (2004), and Pham (2004) raised important questions. This response elaborates on some of their themes by addressing the assessment of naive theories, the role of expectations, the influence of metacognitive experiences on consumer choice, as well as parallels between different metacognitive experiences and moods.

Receiving thoughtful and stimulating commentary from three of my favorite consumer researchers, whose work has influenced my own thinking, is a great privilege. In this response, I elaborate on some of the themes of their commentaries (Huber, 2004; Lee, 2004; Pham, 2004), although space constraints do not allow me to do full justice to their thoughts.
\end{abstract}

\section{HOW DO WE ASSESS NAIVE THEORIES?}

I suggested that naive theories of cognition are the link that allows a person to move from accessibility and fluency experiences to a specific judgment (Schwarz, 2004). As Huber (2004, p. 357) noted, "it is difficult to account for the behavior without positing something like the existence of these naive theories." But he rightly worries that this assumption introduces too much flexibility, allowing the researcher ex post facto to postulate any theory that makes sense of the data. This problem is compounded when we assume that "naive theories are generally neither known nor articulated by the respondent" (Huber, 2004, p. 357). In my reading, the latter conclusion is too strong; naive theories are amenable to empirical exploration and experimental testing. The question is, how?

On the one hand, the inference process is usually implicit and people will rarely be able to report on it introspectively (cf. Nisbett \& Wilson, 1977), rendering think-aloud protocols uninformative. On the other hand, asking people to list what makes it easy or difficult to think of many examples of an event produces a list that covers most of the naive theories of accessibility I discussed. Moreover, asking people whether they agree with naive theories presented to them reveals a remarkable level of consensus. Worried by Huber's (2004) concerns, I presented the naive theories discussed in Schwarz (2004) to 14 undergraduates, not majoring in psy-

Requests for reprints should be sent to Norbert Schwarz, Institute for Social Research, University of Michigan, Ann Arbor, MI 48104-1248. E-mail: Nschwarz@umich.edu chology, either in an affirmative or negated form. All 14 agreed (or rejected the negation) that "the more examples exist, the easier it is to bring some to mind; details of recent events are easier to recall than details of distant events; examples from categories that are well represented in memory are easier to recall than examples from categories that are poorly represented in memory; the more I know about something the easier it is to come up with examples; and things that are important to me are better represented in memory than things that are unimportant." Agreement was lower (9 out of 14) for "plausible and compelling arguments are easier to remember than specious ones." Similarly, all 14 agreed that "familiar (previously seen) material is easier to process; distraction makes information more difficult to process" and "it is easier to perceive a stimulus when it is shown with high rather than low clarity" or "shown for a long rather than short duration." In contrast, all rejected the suggestion that "when something is easy to read it is likely to be true"--but 12 out of 14 agreed that "when one hears something often, there is probably something to it." Of course, it is the latter rather than the former naive theory that underlies the effect of processing fluency on judgments of truth and being aware that the statement only seems familiar because it was easy to read would presumably eliminate the effect.

Theories of this type are brought to mind by task requirements, or can be induced through experimental procedures (e.g., Winkielman \& Schwarz, 2001), with the broad consensus ensuring that enough people draw on the same theory to produce systematic effects. This is sufficient to test theoretical assumptions about the role of naive theories in experience-based judgment, putting concerns about their "unverifi- 
able nature" (Huber, 2004, p. 357) to rest. Nevertheless, some individuals will draw on highly idiosyncratic theories that we may never capture, resulting in "deviant" and surprising responses that may nevertheless be compatible with the general process assumptions, given their naive theory. I am not bothered by this possibility. The key goal of cognitive research is the development of general process models that predict most of the people most of the time (and on my optimistic days I comfort myself with the assumption that even the others may follow the general model, albeit with idiosyncratic content).

\section{THEORY-BASED CORRECTION}

Taking the role of naive theories to the next level, Lee (2004) suggested that people may engage in theory-based corrections under conditions of high processing motivation. Specifically, Rothman and Schwarz (1998) argued that people draw on their accessibility experiences when processing motivation is low, but turn to recalled content when processing motivation is high. As an alternative account, Lee (p. 350) suggests that highly motivated individuals may become aware "that their initial response has been biased by their metacognitive experience of accessibility ease" and may try to correct for this influence by adjusting their judgment, consistent with models of theory-driven correction (e.g., Strack \& Hannover, 1996; Wilson \& Brekke, 1994). The Rothman and Schwarz results do not allow us to distinguish between these possibilities. However, these divergent process assumptions result in differential predictions under specific conditions, rendering them highly testable.

When people become aware of a possible biasing influence, they have two options to avoid the bias: They can either turn to other inputs to arrive at a judgment or they can correct their judgment to counter the bias. Reliance on alternative inputs requires that such inputs are accessible, which is the case in the "few/many-thoughts paradigm" used by Rothman and Schwarz (1998), where participants can switch from their accessibility experiences to the substantive thoughts listed. If they relied on these thoughts, their judgments should resemble the judgments of yoked participants, who read those thoughts without experiencing the ease or difficulty that was associated with their generation (for an example, see Wänke, Bless, \& Biller, 1996). When alternative inputs are not available, people can correct for a perceived bias by adjusting their judgment. Appropriate adjustments require that they assess the likely size of the bias, which is a tricky task. In most cases, people overestimate the bias and therefore "overcorrect" their judgments, resulting in a bias in the opposite direction (e.g., Strack, Schwarz, Kübler, \& Wänke, 1993; for reviews, see Strack \& Hannover, 1996; Wilson \& Brekke, 1994). Accordingly, the judgments of highly motivated participants should be more extreme than the judgments of their yoked counterparts when highly motivated individuals en- gage in theory-based correction, as Lee (2004) suggests, consistent with the common observation of overcorrection.

I assume that both processes can be observed, depending on the availability of alternative inputs. In the few/many-thoughts paradigm, alternative inputs in the form of generated thoughts are always highly accessible. The bulk of the available work on mental contamination and correction suggests that such alternative inputs will be used, making theory-driven correction less likely. In the absence of alternative inputs, however, theory-based correction is the dominant route. Oppenheimer (2004) has documented spontaneous corrections for accessibility experiences in contexts where alternative inputs may not be highly accessible. Unfortunately, his experiments lack controls that would allow the identification of "overcorrection" effects. Given that most manipulations of processing fluency do not provide relevant alternative inputs, theory-based correction may be the most likely route for perceived undue influences of fluency experiences. These conjectures provide a promising avenue for further experimentation.

\section{EXPECTATIONS}

As Huber (2004) and Lee (2004) point out, expectations play a critical role in metacognitive experience. They do so in several ways. First, our subjective experience tracks changes rather than states, from the experience of temperature and brightness to our affective response to pleasant and unpleasant stimuli and our sense of ease or difficulty. Accordingly, our adaptation level or-in more cognitive terms-our expectations based on previous experience, influence how we experience the next stimulus. This route results in differential subjective experiences of the same stimulus and influences experience-based judgments by varying the experiential information itself. Second, changes in the experience and deviations from expectations capture attention and make it more likely that the experience is considered when forming a judgment. Finally, some expectations offer naive theories that explain the experience. When participants are told, for example, that most others find a task difficult (as in Menon \& Rhagubir, 2003; Schwarz et al., 1991; Winkielman, Schwarz, \& Belli, 1998), the experienced difficulty is not only expected but also explained: it is due to the nature of the task. This attribution renders the experience uninformative for other judgments and fosters reliance on recalled content as an alternative input (e.g., Schwarz et al., 1991). Only the latter two pathways for the influence of expectations are likely to depend on the available processing resources.

Unfortunately, most experiments addressing "expectation" effects have relied on manipulations that also entail an explanation of the experience in terms of a theory that renders the experience irrelevant to the judgment at hand. Future research may fruitfully explore manipulations that avoid this 
problem and may also attend to the alternative influences of expectations noted earlier.

\section{CONSUMER CHOICE}

To date, the bulk of the available research has addressed the role of metacognitive experiences in judgment and my review paid limited attention to consumer choice. In fact, there are plausible reasons why choice may sometimes be less affected by these experiences, as Huber (2004) notes. Nevertheless, the limited available evidence indicates a more pervasive role of metacognitive experiences than Huber's cautious discussion suggests.

Consumer researchers have repeatedly observed that difficult choices increase deferral (e.g., Dhar, 1997) and the selection of a compromise option (e.g., Simonson \& Tversky, 1992). Extending this work, Novemsky, Dhar, Simonson, and Schwarz (2003) observed that metacognitive difficulty experiences, induced without changing the choice set, have the same effect. In one study, we presented descriptions of three digital cameras in an easy to read or difficult to read font, thus manipulating processing fluency. When the font was easy to read, $56 \%$ chose the compromise option-yet $71 \%$ did so when the font was difficult to read. Acknowledging this difficulty ("Sorry, this is how it downloads from a Web site.") eliminated this influence, reducing the selection of the compromise option to $57 \%$. In other studies, we asked participants to rate how difficult it would be to provide 10 (or 2 ) reasons for a choice. Again, the compromise effect increased from $22 \%$ in the 2-reason condition to $44 \%$ in the 10 -reason condition. In another experiment, $61 \%$ of the participants deferred choice in the 10-reason condition, whereas only $49 \%$ did so in the 2 -reason condition. Findings of this type suggest that the fluency with which consumers can form a preference exerts a strong influence on whether they buy anything at all (or wait for a better opportunity) and influences what they buy. Consistent with the latter possibility, Lee (2002) observed that conceptual and perceptual fluency determined brand selection. Her findings also indicated that it is not always useful to gloss over distinctions between perceptual and conceptual fluency, as I did in my review. As Lee (2004, p. 354) noted, "brands that are perceptually fluent are more likely to be selected in stimulus-based versus memory-based choice situations, and the reverse is true for brands that are conceptually fluent."

Based on these initial findings, I am confident that exploring the role of metacognitive experiences in consumer choice provides a promising avenue for future research. This research could also fruitfully explore the role of subjective experiences when the experienced difficulty is imposed by the choice set itself, as has traditionally been the case in consumer research. Based on the present theorizing, substantive features of the choice alternatives (e.g., Dhar, 1997; Garbarino \& Edell, 1997; Simonson \& Tversky, 1992) should exert little influence when the difficulties they impose are misattributed to another source, indicating that the influence of objective features of the alternatives is mediated by subjective processing experiences.

\section{THE BIG PICTURE}

Accessibility and fluency experiences are two exemplars of the broader class of experiential information, which also includes moods, emotions, physical arousal, and other bodily sensations (for a review, see Schwarz \& Clore, 1996). Pham's commentary (2004) offers a scholarly integration of the basic principles underlying the use of experiential information, drawing primarily on moods and emotions. As his review illustrates, Pham's own work has advanced the feelings-as-information approach far beyond our initial research (Schwarz \& Clore, 1983; for a retrospective, see Schwarz \& Clore, 2003). Whereas our work focused mostly on the perceived informational value of the feeling itself, Pham's studies identified numerous other variables that influence the use of feelings as information, from their relevance to the goal (e.g., Pham, 1998) to the extent that people think they can trust their own feelings (e.g., Pham \& Avnet, 2004).

His discussion of the "rules of interpretation" also indicates that the conclusions we draw from our moods are (nearly) as varied as the conclusions we draw from metacognitive experiences. In both cases, the experiential information is brought to bear on the task at hand and this task determines the rules of interpretation that are employed. The resulting interplay of declarative and experiential information accounts for much of the variability in human response. When our feelings are ecologically valid, that is, integral to the task, they provide important goal- and task-relevant information that facilitates adaptive reactions. Unfortunately, however, the window on our experience is often foggy and we cannot tell if our feelings are due to some incidental influence, leading us down a road we would rather not take.

\section{REFERENCES}

Dhar, R. (1997). Consumer preference for the no-choice option. Journal of Consumer Research, 24, 215-231.

Garbarino, E. C., \& Edell, J. A. (1997). Cognitive effort, affect, and choice. Journal of Consumer Research, 24, 147-158.

Huber, J. (2004). A comment on metacognitive experiences and consumer choice. Journal of Consumer Psychology, 14, 356-359.

Lee, A. Y. (2002). Effects of implicit memory on memory-based versus stimulus-based brand choice. Journal of Marketing Research, 39, 440-454.

Lee, A. (2004). Prevalence of metacognitive routes to judgment: Comment Journal of Consumer Psychology, 14, 349-355.

Menon, G., \& Raghubir, P. (2003). Ease of retrieval as an automatic input in judgments: A mere-accessibility framework? Journal of Consumer Research, 30, 230-243. 
Nisbett, R. E., \& Wilson, T. D. (1977). Telling more than we can know: Verbal reports on mental processes. Psychological Review, 84, 231-259.

Novemsky, N., Dhar, R., Simonson, I., \& Schwarz, N. (2003, October). Preference fluency and its effects on no-choice, compromise, and attraction effects. In N. Novemsky (Chair), New frontiers in the construction of preferences. Symposium conducted at the meeting of the Association for Consumer Research, Toronto, Ontario, Canada.

Oppenheimer, D. (2004). Spontaneous discounting of availability in frequency judgment tasks. Psychological Science, 15, 100-105.

Pham, M. T. (1998). Representativeness, relevance, and the use of feelings in decision making. Journal of Consumer Research, 25, 144-159.

Pham, M. T. (2004). The logic of feeling. Joumal of Consumer Psychology, 14, 360-369.

Pham, M. T., \& Avnet, T (2004). Ideals and oughts and the reliance on affect versus substance in persuasion. Journal of Consumer Research, 30, $503-518$

Rothman, A. J., \& Schwarz, N. (1998). Constructing perceptions of vulnerability: Personal relevance and the use of experiential information in health judgments. Personality and Social Psychology Bulletin, 24, 1053-1064.

Schwarz, N. (2004). Metacognitive experiences in consumer judgment and decision making. Journal of Consumer Psychology, 14, 332-348.

Schwarz, N., Bless, H., Strack, F., Klumpp, G., Rittenauer-Schatka, H., \& Simons, A. (1991). Ease of retrieval as information: Another look at the availability heuristic. Journal of Personality and Social Psychology, 6I, 195-202.

Schwarz, N., \& Clore, G. L. (1983). Mood, misattribution, and judgments of well-being: Informative and directive functions of affective states. Journal of Personality and Social Psychology, 45, 513-523.
Schwarz, N., \& Clore, G. L. (1996). Feelings and phenomenal experiences. In E. T. Higgins \& A. Kruglanski (Eds.), Social psychology: Handbook of basic principles (pp. 433-465). New York: Guilford.

Schwarz, N., \& Clore, G. L. (2003). Mood as information: 20 years later. Psychological Inquiry, 14, 296-303.

Simonson, I., \& Tversky A. (1992). Choice in context: Tradeoff contrast and extremeness aversion. Journal of Marketing Research, 29, 281-295.

Strack, F., \& Hannover, B. (1996). Awareness of influence as a precondition for implementing correctional goals. In P. M. Gollwitzer \& J. A. Bargh (Eds.), The psychology of action (pp. 579-595). New York: Guilford.

Strack, F., Schwarz, N., Bless, H., Kübler, A., \& Wänke, M. (1993). Awareness of the influence as a determinant of assimilation versus contrast. $E u-$ ropean Journal of Social Psychology, 23, 53-62.

Wänke, M., Bless, H., \& Biller, B. (1996). Subjective experience versus content of information in the construction of attitude judgments. Personality and Social Psychology Bulletin, 22, 1105-1113.

Wilson, T. D., \& Brekke, N. (1994). Mental contamination and mental correction: Unwanted influences on judgments and evaluations. Psychological Bulletin, 116, 117-142.

Winkielman, P., \& Schwarz, N. (2001). How pleasant was your childhood? Beliefs about memory shape inferences from experienced difficulty of recall. Psychological Science, 12, 176-179.

Winkielman, P., Schwarz, N., \& Belli, R. F. (1998). The role of ease of retrieval and attribution in memory judgments: Judging your memory as worse despite recalling more events. Psychological Science, 9, 124-126.

Received: February 19, 2004 